\title{
Effect of Education of Principles of Drug Prescription and Calculation through Lecture and Designed Multimedia Software on Nursing Students' Learning Outcomes
}

\author{
Sousan Valizadeh ${ }^{1}$, Hossein Feizalahzadeh ${ }^{2}$, Mina Avari ${ }^{3}$, Faza Virani ${ }^{4}$
}

${ }^{1}$ Associate Professor, Department of Pediatrics Nursing, Faculty of Nursing and Midwifery, Tabriz University of Medical Sciences, Tabriz, Iran

2 Assistant Professor, Department of Medical Surgical Nursing, Faculty of Nursing and Midwifery, Tabriz University of Medical Sciences, Tabriz, Iran

${ }^{3}$ M.Sc. Student of Nursing, Tabriz University Student Research Committee, Tabriz University of Medical Sciences, Tabriz, Iran

${ }^{4}$ M.Sc. of Nursing, Educational Member, Department of Medical Surgical Nursing, Faculty of Nursing and Midwifery, Tabriz University of Medical Sciences, Tabriz, Iran

\section{Type of article: Original}

\begin{abstract}
Introduction: Medication errors are risk factors for patients' health and may have irrecoverable effects. These errors include medication miscalculations by nurses and nursing students. This study aimed to design a multimedia application in the field of education for drug calculations in order to compare its effectiveness with the lecture method.

Methods: This study selected 82 nursing students of Tabriz University of Medical Sciences in their second and third semesters in 2015. They were pre-tested by a researcher-made multiple-choice questionnaire on their knowledge of drug administration principles and ability to carry out medicinal calculations before training and were then divided through a random block design into two groups of intervention (education with designed software) and control (lecturing) based on the mean grade of previous semesters and the pre-test score. The knowledge and ability post-test was performed using the same questions after 4 weeks of training, and the data were analyzed with IBM SPSS 20 using independent samples t-test, paired-samples t-test, and ANCOVA.

Results: Drug calculation ability significantly increased after training in both the control and experimental groups $(p<0.05)$. However, no significant difference emerged between the two groups in terms of medicinal calculation ability after training $(\mathrm{p}>0.05)$. The results showed that both training methods had no significant effect on study participants' knowledge of medicinal principles $(\mathrm{p}>0.05)$, whereas the score of knowledge of medicinal principles in the control group increased non-significantly. The results of the Kolmogorov-Smirnov test show that, since $p>0.05$, the data in the variable of knowledge of drug prescription principles and ability of medicinal calculations had a normal distribution.

Conclusion: The use of educational software has no significant effect on nursing students' drug knowledge or medicinal calculation ability. However, an e-learning program can reduce the lecture time and cost of repeated topics, such as medication, suggesting that it can be an effective component in nurse education programs.

Keywords: Medication calculation, Nursing students, Multimedia software, Lecture, Principles of drug administration
\end{abstract}

\section{Introduction}

The implementation of patients' medication orders is a main, critical role of nurses (1) and nursing students (2). They should be able to correctly and accurately calculate the amount, volume, and rate of prescribed medications and safely carry out pharmaceutical orders (3). Thus, they require knowledge and skills in various fields, including a

\section{Corresponding author:}

Mina Avari, Tabriz University Student Research Committee, Tabriz University of Medical Sciences, Tabriz, Iran. Tel: +98.9143138362, Email: minaavari@yahoo.com

Received: April 24, 2016, Accepted: June 03, 2016, Published: July 2016

iThenticate screening: June 01, 2016, English editing: June 28, 2016, Quality control: July 03, 2016

(C) 2016 The Authors. This is an open access article under the terms of the Creative Commons Attribution-NonCommercialNoDerivs License, which permits use and distribution in any medium, provided the original work is properly cited, the use is non-commercial and no modifications or adaptations are made. 
variety of diseases, pharmacology, and mathematical calculations (4). A lack of such knowledge and skills in pharmacology and incorrect pharmaceutical calculations are factors affecting medication errors (5) and can result in a prolonged length of stay, increased costs, and sometimes severe and irrecoverable damage and even death (6). In addition, medication error is a common and serious problem in hospitals (7). Lectures are one of the oldest methods of training; in this teacher-centered method, students are inactive, and their individual differences are not considered. Although lectures are the most appropriate teaching method in certain circumstances (8), many studies have reported the superiority of learner-centered approaches (9). Theoreticians believe that education through common methods is no longer effective due to their dependence to particular times and places (10). On the other hand, participation in these classes require relocation and accommodation of students and professors, as well as additional costs (11). Due to changes and advances in technology in the last few decades, the use of new teaching methods in science including medicine as well as the revision of conventional approaches seems inevitable (8). Nursing and its education have also had to adapt to these changes (12). Furthermore, due to the increasing rate of nursing students and insufficient number of professors in nursing schools, methods other than lectures are required (13). E-learning is a relatively new training method and includes the use of IT-based educational applications, such as computer, internet, mobile, and other methods (8). Using computers as the primary means of teaching is known as computer-assisted instruction (CAT) (12). CAT is presented using the internet, web, satellite broadcasting, multimedia software, virtual and distance learning, and computer simulation (11). Flexibility, learners' activity, feedback, and reproducibility of educational programs are some advantages of this method compared to other methods (14). According to the American Institute of Medicine, 98,000 people in the United States die due to medical errors each year, 7,000 of which are due to medication errors. In other words, one out of every 10 hospitalized patients in America is injured due to medication errors. Medication errors are the eighth leading cause of death in the United States (15). According to studies conducted in Europe, 19\%-28\% of patients are exposed to this risk (5). Due to obstacles to reporting, the exact statistics of medication errors are not available in Iran, although this seems to be a large amount (16). In one study, the incidence of medication errors in a hospital in Kermanshah was $79.2 \%$ (17). Although a lack of knowledge and skills, resulting in pharmacology and pharmaceutical miscalculations, is the most important cause of medication errors by nurses and nursing students $(18,19)$, not enough attention is paid to this issue in nursing courses in Iran (20). This is especially important in the case of lifesaving drugs (5). According to a study by Ahmadieh, nursing students have problems with math skills in pharmaceutical calculations; thus, it seems better to include these topics in their curriculum (21). In one study, nursing students attributed their poor pharmacology knowledge to insufficient teaching time as well as failure to comply with their practical needs (5). The results of these studies suggest the high prevalence of medication errors in nurses and nursing students as well as the need to pay attention to education in this regard. Given the prevalence of medicinal errors and the importance of risk reduction as a critical debate in the field of risk management and improvement of hospitals' quality (22), the need exists for basic education in this context. Yet comparing the effectiveness of different educational methods for nurses and nursing students has had mixed results, necessitating further research in this area. In addition, in a majority of the existing studies, the necessary explanations regarding CAT programs are not provided or these programs are not designed based on learning principles. Therefore, the present study was carried out to address these concerns in order to facilitate nursing students' education related to the calculation of doses of life-saving drugs in order to take a small step toward the improvement of a community's health.

\section{Material and Methods}

Regarding the educational needs of nursing students as well as the nursing curriculum, educational content was first prepared in this quasi-experimental (interventional) study by reviewing the literature and using scientific resources, including Fundamentals of Nursing by Potter and Perry, Dugas' drug dosage calculation books, drug administration guidelines, and surveys with several clinical pharmacologists and nursing professors. This content included a combination of texts, images, sounds, animations, and videos and focused on empowering nursing students in the field of prescription and medication calculation.

\subsection{Development of multimedia and educational software}

Within the framework of educational objectives, digital cameras and video cameras were used to take photographs and videos from actual scenes. After preparing the raw materials, lecture sounds were recorded on educational slides and edited using Ispring Suite 7; the prepared files were then extracted into the Flash format in Ispring Suite 7. The gallery part was designed using Articulate Storyline 2, and the typed content was converted to Flash format using Flash Paper. Pictures on the gallery, compact discs, and other issues were designed and edited using PhotoShop CS. Finally, all content and images were prepared on a compact disc using Autoplay Media Studio 8. This educational 
application used research findings from the e-learning field, including 10 principles of the Meyer multimedia design, educational materials' evaluation criteria, and a checklist assessing educational materials.

\subsection{Experimental design}

In order to measure individuals' knowledge of drug prescription principles and ability to carry out medicinal calculations, a questionnaire was prepared in the field of educational content. The knowledge questionnaire consisted of 10 four-choice items; to eliminate the possibility of chance, the fourth choice in all questions was "I do not know." Correct and incorrect answers were scored 1 and 0 , respectively. The validity of the questionnaire was analyzed by 10 professors of nursing and midwifery faculty at Tabriz University, and its reliability was calculated and confirmed using Cronbach's alpha on 30 students of Tabriz University who were not in the study sample. The ability questionnaire contained 20 four-choice items; to eliminate the possibility of chance, the fourth choice in all questions was "I do not know." Correct and incorrect answers were scored 1 and 0 , respectively. The validity of the questionnaire was analyzed by 10 professors of nursing and midwifery faculty at Tabriz University, and its reliability was calculated and confirmed using Cronbach's alpha on 30 students of Tabriz University who were not in the study sample.

\subsection{Experimental study and sampling method}

Inclusion criteria for this study were studying in the second or third semesters of the nursing program and providing informed consent to participate in the research; exclusion criteria were a history of clinical experience and/or refusal to continue participating in the study. An intervention was performed in the first semester of the 2015-2016 academic year for all second and third semester nursing students $(n=82)$. Due to the small population size in this study, the sample size was considered equal to the population size. After the necessary coordination with authorities of Tabriz University of Medical Sciences and School of Nursing as well as the acquisition of necessary licenses, the researcher attended the class of eligible students, explained the research objectives, and obtained their consent to participate in the study. Due to limitations in space and facilities, all steps were done separately for second and third semester students. After providing written consent to participate in the research and before starting the education, all students were pre-tested using the knowledge and ability questionnaires. Demographic characteristics including age, gender, marital status, work experience in hospitals or clinics, passing pharmacology course, and first and second semesters' GPA were gathered during the same session. Twenty-six were excluded based on the exclusion criteria. In the next stage, the pre-test score and first (second) semester GPA averages were calculated for second (third) semester students. The resulting scores were arranged in ascending order, and based on the scores students were categorized into two groups of intervention for training with the produced multimedia software and control for teaching through lectures. Each group received three two-hour sessions, with a week interval between two sessions. A conference room equipped with a computer with a CD burner was used for the software group after coordinating efforts with school officials. A computer was assigned to each student, and all students used hands-free technology to avoid sound interference. The method for using the software was then explained, and it was ensured that all students reviewed the subjects at least once. Finally, students in the intervention group received a copy of the software. Education of the control group was performed in a classroom of the faculty after coordination with school officials and one of the professors. The training program was provided by a professor in a lecture format using PowerPoint for both semesters. All educational materials were given to the students in the control group in a PDF format so they could review them, if required. Four weeks after the intervention, all students from both groups completed the post-test for knowledge and ability, which contained the same questions as the pre-test; a software evaluation form was also given to the intervention group. Some gifts were offered to students participating in the study to encourage them and demonstrate appreciation.

\subsection{Statistical analysis}

The knowledge and ability post-test was performed using the same questions after 4 weeks of training. The data were analyzed with SPSS-20 and independent sample t-test, paired-samples t-test, and ANCOVA.

\section{Results}

\subsection{Evaluation of students}

An evaluation of students' individual characteristics showed that the frequency of women in the intervention group and in the control group was $5.54 \%$ and $56.4 \%$, respectively. All students in the intervention group were single while one was married to the control group. The mean ages in the intervention and control groups were 20.45 and 21.43 years, respectively. The average GPA of the first semester was 15.46 in the intervention group and 15.22 in 
http://www.ephysician.ir

the control group. The average GPA of the second semester was 15.44 in the intervention group and 14.7 in the control group (Table1).

Table 1. Evaluation of the individual characteristics

\begin{tabular}{|l|l|l|l|}
\hline Personal details & Intervention group & Control group \\
\hline \multirow{2}{*}{ Sex; $\mathrm{n}(\%)$} & Male & $15(45.5)$ & $10(43.5)$ \\
\cline { 2 - 4 } & Female & $18(54.5)$ & $13(56.5)$ \\
\hline \multirow{2}{*}{ Married status } & Married & 0 & $1(4.3)$ \\
\cline { 2 - 4 } & Single & $33(100)$ & $22(95.7)$ \\
\hline Age, Mean \pm SD & $20.45(2.17)$ & $21.43(3.08)$ \\
\hline First Semester Average, Mean \pm SD & $15.46(1.46)$ & $15.22(1.55)$ \\
\hline \multicolumn{2}{|l|}{ Second Semester Average, Mean \pm SD } & $15.44(1.46)$ & $14.7(1.38)$ \\
\hline
\end{tabular}

\subsection{Hypothesis evaluation}

The results of the Kolmogorov-Smirnov test show $\mathrm{p}>0.05$; therefore, the data in the variable of knowledge of drug prescription principles and ability of medicinal calculations had a normal distribution (Table 2). The regression slope suggests that no significant interaction existed between the independent variable (group) and the confounding variable (pre-test) in scores of knowledge of drug prescription principles $(\mathrm{F}=1.392, \mathrm{p}>0.05)$ and scores of drug calculations ability $(\mathrm{F}=0.075, \mathrm{p}>0.05)$. In other words, the slopes of regression in scores of both variables are homogeneous (Table 3). The results of Levene's assumptions confirmed the equality of variances of groups in society $(\mathrm{F}=3.77, \mathrm{p}>0.05)$; in other words, scores of knowledge of drug prescription principles $(\mathrm{F}=3.77, \mathrm{p}>0.05)$ and the distribution of scores of medicinal calculation ability $(\mathrm{F}=0.075, \mathrm{p}>0.05)$ were equal in both intervention and control groups (Table 4).

Table 2. Distribution of pre-test and post-test scores in the two groups of intervention and control and ability of medicinal calculations

\begin{tabular}{|c|c|c|c|c|c|}
\hline \multirow{2}{*}{\multicolumn{2}{|c|}{ Variables }} & \multicolumn{2}{|l|}{ Pre Test } & \multicolumn{2}{|l|}{ Post Test } \\
\hline & & Intervention & Control & Intervention & Control \\
\hline \multirow{3}{*}{$\begin{array}{l}\text { Knowledge of drug prescription } \\
\text { principles }\end{array}$} & No & 33 & 23 & 33 & 23 \\
\hline & $\begin{array}{l}\text { Kolmogorov-Smirnov } \\
\text { Z }\end{array}$ & 1.297 & 1.16 & 1.093 & 1.19 \\
\hline & p-value & 0.069 & 0.133 & 0.184 & 0.123 \\
\hline \multirow[t]{3}{*}{ Ability of medicinal calculations } & No & 33 & 23 & 33 & 23 \\
\hline & $\begin{array}{l}\text { Kolmogorov-Smirnov } \\
\text { Z }\end{array}$ & 1.329 & 1.382 & 1.294 & 0.969 \\
\hline & p-value & 0.059 & 0.044 & 0.07 & 0.305 \\
\hline
\end{tabular}

Table 3. Covariance analysis to study regression slope

\begin{tabular}{|l|l|l|l|l|l|l|}
\hline \multicolumn{2}{|l|}{ Variables } & $\begin{array}{l}\text { Sum } \\
\text { Square }\end{array}$ & $\begin{array}{l}\text { Degrees of } \\
\text { freedom }\end{array}$ & $\begin{array}{l}\text { Mean } \\
\text { Square }\end{array}$ & F & Sig. \\
\hline $\begin{array}{l}\text { Knowledge of drug prescription } \\
\text { principles }\end{array}$ & $\begin{array}{l}\text { Group pre- } \\
\text { test }\end{array}$ & 7.48 & 1 & 7.48 & 1.392 & 0.244 \\
\cline { 2 - 7 } & Errors & 279.51 & 52 & 5.375 & & \\
\hline Ability of medicinal calculations & $\begin{array}{l}\text { Group pre- } \\
\text { test }\end{array}$ & 83.927 & 1 & 83.927 & 3.26 & 0.077 \\
\cline { 2 - 8 } & Errors & 1337.84 & 52 & 25.72 & & \\
\hline
\end{tabular}

Table 4. Levene's test for comparison of variance in scores between the two groups

\begin{tabular}{|l|l|l|l|l|}
\hline Variables & $\mathrm{F}$ & $\mathrm{df}_{1}$ & $\mathrm{df}_{2}$ & Sig. \\
\hline Knowledge of drug prescription principles & 3.772 & 1 & 54 & 0.057 \\
\hline Ability of medicinal calculations & 0.075 & 1 & 54 & 0.785 \\
\hline
\end{tabular}

\subsection{Results evaluation}

With the approval of the default assumptions, the covariance analysis results are as follows. The results of ANCOVA performed on scores of knowledge of drug prescription principles and ability of medicinal calculations in 
both groups (intervention and control) are provided in Table 5. In this analysis, the pre-test scores have been under statistical control, meaning that the effect of pre-test scores was removed from post-test scores and the two groups were compared based on the residual variance. The results showed no significant difference between the control and intervention groups in terms of scores of knowledge of drug prescription principles $(F=2.10, p>0.05)$. There was also no significant difference in scores of medicinal calculation ability between the intervention and control groups $(\mathrm{F}=0.132, \mathrm{p}>0.05)$. The results in Table 6 show that the mean score of knowledge of drug prescription principles in the pre-test was 5.54 in the intervention group and 5.43 in the control group. The post-test scores of knowledge of drug prescription principles without controlling the confounding variable was 5.27 in the intervention group and 6.13 in the control group. As shown in Table 6, the mean and standard error of scores of knowledge of drug prescription principles in both groups after controlling the confounding variable was 5.24 in the intervention group and 6.16 in the control group, with no significant difference with each other $(\mathrm{F}=2.10, \mathrm{p}>0.05)$. The independentsamples t-test also showed that the intervention and control groups had no significant difference in either the pre-test $(\mathrm{p}=0.862)$ or post-test $(\mathrm{p}=0.234)$, suggesting no impact of the application in the intervention group. The paired $\mathrm{t}$-test showed that the post-test and pre-test scores of knowledge of drug prescription principles in the control group were similar $(\mathrm{p}=0.084)$. In the intervention group, the post-test and pre-test scores were also similar $(\mathrm{p}=0.958)$. Unchanged pre-test and post-test scores in both groups represent a lack of educational impact through lecture and training software in promoting knowledge of drug prescription principles.

The results summarized in Tables 4 through 6 show that the mean score of medicinal calculation ability in the pretest was 2.39 in the intervention group and 1.73 in the control group. The post-test scores of medicinal calculation ability without controlling the confounding variable was 5.96 in the intervention group and 4.86 in the control group. As shown in Tables 4 through 6, the mean and standard error of scores of medicinal calculation ability in both groups after controlling the confounding variable was 5.73 in the intervention group and 5.21 in the control group, with no significant difference with each other $(\mathrm{F}=0.132, \mathrm{p}>0.05)$. The independent samples t-test also indicated that the intervention and control groups showed no significant difference in either the pre-test $(\mathrm{p}=0.395)$ or post-test $(\mathrm{p}=0.48)$, suggesting no impact of the application in the intervention group. The paired $\mathrm{t}$-test showed that the post-test scores of medicinal calculation ability had a significant increase compared to the pre-test in the control group ( $\mathrm{p}=0.001$ ). A significant increase was also seen in the post-test compared to the pre-test in the intervention group ( $\mathrm{p}=0.003$ ). Increased post-test scores in both groups represent the impact of education through lecture and training software in the promotion of medicinal calculation ability.

Table 5. Analysis of covariance between the two groups in knowledge of drug prescription principles and ability of medicinal calculations

\begin{tabular}{|l|l|l|l|l|l|l|}
\hline Variables & $\begin{array}{l}\text { Sum of } \\
\text { Squares }\end{array}$ & df & $\begin{array}{l}\text { Mean } \\
\text { Squares }\end{array}$ & Sig. & $\begin{array}{l}\text { Eta } \\
\text { squared }\end{array}$ \\
\hline \multirow{2}{*}{$\begin{array}{l}\text { Knowledge of drug prescription } \\
\text { principles }\end{array}$} & Groups & 11.384 & 1 & 11.384 & 0.153 & 0.038 \\
\cline { 2 - 8 } & Pre-test & 84.157 & 1 & 84.157 & 0.000 & 0.227 \\
\hline & error & 286.99 & 53 & 5.415 & & \\
\hline Ability of medicinal calculations & Groups & 3.55 & 1 & 3.55 & 0.717 & 0.002 \\
\cline { 2 - 8 } & Pre-test & 339.80 & 1 & 339.8 & 0.001 & 0.193 \\
\cline { 2 - 8 } & error & 1421.77 & 53 & 26.82 & & \\
\hline
\end{tabular}

Table 6. Comparison of mean and standard deviation of knowledge and ability scores in the two groups in pre-test, post-test, and post-test after controlling the intervention variables

\begin{tabular}{|l|l|l|l|l|l|}
\hline \multicolumn{2}{|l|}{ Variables } & Pre-test & Post-test & $\begin{array}{l}\text { Post-test, after controlling } \\
\text { pre-test variables }\end{array}$ & p-value \\
\cline { 3 - 6 } \multicolumn{2}{|c|}{} & Mean (SD) & Mean (SD) & Mean (SE) & \\
\hline \multirow{2}{*}{$\begin{array}{l}\text { Knowledge of drug } \\
\text { prescription principles }\end{array}$} & Control & $5.43(2.46)$ & $6.13(2.43)$ & $6.165(0.485)$ & 0.084 \\
\cline { 2 - 6 } & Treatment & $5.54(2.251)$ & $5.27(2.74)$ & $5.24(0.405)$ & 0.598 \\
\cline { 2 - 6 } & p-value & 0.862 & 0.234 & & 0.001 \\
\hline \multirow{2}{*}{$\begin{array}{l}\text { Ability of medicinal } \\
\text { calculations }\end{array}$} & Control & $1.73(1.98)$ & $4.86(5.52)$ & $5.21(1.08)$ & 0.003 \\
\cline { 2 - 6 } & Treatment & $2.39(3.25)$ & $5.96(5.83)$ & $5.73(0.90)$ & \\
\cline { 2 - 5 } & p-value & 0.395 & 0.481 & & \\
\hline
\end{tabular}




\section{Discussion}

Learning practical skills before engaging in practical work is a critical issue in nursing care. Studies have shown that novice nurses and nursing students have trouble in providing proper care to patients and calculating correct dosages (23-25). Acquiring practical skills should lead to students' mastery and ability to easily use such skills in practical and real conditions (26-28). The use of new educational methods, including software and instructional videos, offers new approaches in this regard. According to previous studies, e-learning results in a $20 \%-30 \%$ increase in learning above the lecture method (8). However, some experts believe that e-learning is a supplement to common teaching methods (11) and thus suggest a combined learning approach. According to Shirley et al., voice communication between the learner and teacher affects effectiveness of this training method (11). Combining videos, images, and animations with educational texts increases interest in learning and provides a balance in visual, written, and aural learning (10). In other words, the purpose of using multimedia software as a derivative of e-learning (29) is to promote students' clinical skills and decision-making power (30). Using this method also creates the right conditions for individual learning according to individuals' capacity (11). Assuming that multimedia design compatible with human functions is more effective than non-compatible type, planners should adopt a human-centered approach when designing multimedia educational programs, because it focuses on using technology to help the power of human cognition. Although there are different cognitive, structural, and behavioral theories in the field of learning, only the Meyer multimedia theory has considered this issue $(14,31)$. In Koohestani et al.'s (2008) study, $48.5 \%$ of nursing students produced medication errors. Bindler and Bayne (1991) studied 110 nurses to evaluate medicinal calculation ability; $81 \%$ of nurses scored less than $90 \%$ and $43.6 \%$ less than $70 \%$. Gladstone (1995) found that more than $50 \%$ of medication errors related to drug amount, of which $30 \%$ stemmed from miscalculation of the amount and infusion rate $(32,33)$. Gillham and Chu (1995) assessed the ability of 158 sophomore nursing students to calculate drug doses using a 10 -item questionnaire; only 55\% of students answered all items correctly. The authors found that students' poor basic knowledge of math was a reason for these numerous mistakes (34). According to another study, limited knowledge of pharmacology was the main reason for Japan's new graduate nurses' mistakes in intravenous drug administration (5). Zahmatkeshan and Nick Pima also showed the prevalence of drug miscalculations among nurses $(35,36)$. Wright's study on the level of math comprehension and skills in sophomore nursing students, performed using a self-made questionnaire and math tests, showed students' significant weakness in basic math calculations (37). According to Shams et al., nursing students' pharmacology knowledge and drug calculation skills of cardiac medicines were not at an acceptable level (38). Koohestani et al. (2008) also indicated that medicinal miscalculations of cardiac drugs are the most common medicinal errors made by nursing students. Haji Hosseini et al. (2012) assessed nursing students' basic skills in pharmacotherapy and intravenous therapies at the end of the third year and found the least skill in calculating the dose of drugs and serum drops (39).

Our results showed that, after training, nursing students' drug calculation ability significantly increased in both the control and experimental groups; this findings is consistent with previous studies stating that knowledge and skills decrease after a while, so nurses may need to repeat courses (11). Studies have shown that most of students' errors are due to simple mistakes in drug calculations. Of 19 sophomore nursing students who failed the first test, only 3 repeated errors after training, and after the third training, all students correctly calculated the dose without error. The results of this study show that repeated trainings can be effective in reducing nursing errors (33). Regarding medication errors, reports show that the most common causes of errors are a lack of pharmacological information $(15.25 \%)$, a lack of attention to the dose in the drug card (13.55\%), and drug miscalculations (11.86\%). In another study, the lack of pharmacological information $(26.52 \%)$ was mentioned as one of students' errors (25). According to Kim et al., compared to a pamphlet, using a CD for teaching motivates students more. Khakbazan et al. observed a significant increase in the mean of awareness after training in the software package group compared to the lecture group (11). Another study showed that the use of educational software along with educational videos significantly improved scores, while the control group using traditional training showed no significant change in the scores $(p>0.05)(10)$. A review article comparing education on drug dosage calculations between two groups through lectures and strategies such as online learning of math and face-to-face training showed that the strategies used were effective for more than 12 months when emphasizing two key points: math skills concepts and the conceptualization of improving and maintaining calculation skills (40). To calculate drug doses correctly, conceptualization and interpretation are also necessary in addition to mathematical knowledge (37). Despite studies that have pointed out the effective role of media-assisted instruction, some studies have suggested that its effects are equal with other methods. In a study by Jeffrise et al. on training skills for performing electrocardiography, no significant difference was observed between two educational groups using multimedia versus conventional methods. Sung et al. compared the effect of training on oral medication administration skills using conventional and multimedia methods; no significant difference was observed in nursing students, although the multimedia group was more satisfied (11). 
Another study found that satisfaction and performance scores of a group trained through online education, videos, and multimedia were associated with better clinical skills compared to the control group (41). Huihao et al. revealed that the use of educational films during physical examination training can improve practical skills more than traditional methods can (42). Using educational videos has led to significant improvements in senior nursing students' knowledge and practical skills compared to the control group (43). Regarding the teaching of implementing drug orders for novice nurses, using a combination of face-to-face training and e-learning improved their medical knowledge (22). But another study to assess the skills of monitoring vital signs with the help of multimedia and using anatomic and physiologic content increased students' practical skills, but not their level of real knowledge (8). Another study about training nursing students in clinical skills using instructional videos showed that, although a film could better complement the lecture, it cannot be perfectly substituted (10). Kaldron did not find a significant difference between the two groups in terms of learning and multimedia (11).

\section{Conclusions}

It has been previously reported that using instructional videos to train nursing students to use clinical skills could better complement lectures; however, they are not a perfect substitute. In addition, no significant difference emerged between learning and multimedia groups in some previous studies. Similarly, this study found no significant difference between the intervention and control groups in terms of education method. However, e-learning programs can reduce lecture time and cost of repeated topics (e.g., medication), suggesting that it can be an effective component in nurse education programs. Therefore, it seems that teaching with software and videos, instead of lectures, can be successful.

\section{Acknowledgments:}

This paper is based on a master's thesis of nursing submitted to Tabriz University of Medical Sciences. The authors wish to thank the vice-chancellor of Tabriz University of Medical Sciences for the financial support of this study.

\section{Conflict of Interest:}

There is no conflict of interest to be declared.

\section{Authors' contributions:}

All authors contributed to this project and article equally. All authors read and approved the final manuscript.

\section{References:}

1) Soozani A, Bagheri H, Pourheydari M. Factors Affecting Medication Errors by Nurses Working in Different Wards of Imam Hossein hospital Shahrood. J Sci Heal. 2007; 2(3): 8-13.

2) Heidari SH, Shahabinejad M, Soltani A, Abdoli F. Rate and type of medication errors and factors in preventing the report of them in the nursing students of Rafsanjan University of Medical Sciences in 2009. Community Hlt J. 2013; 7(2-3): 48-55.

3) Trim J. Clinical skills: a practical guide to working out drug calculations. BJN. 2004; 13(10). doi: 10.12968/bjon.2004.13.10.13050.

4) Koohestani H, Baghcheghi N. Comparing the effects of two educational methods of intravenous drug rate calculations on rapid and sustained learning of nursing students: Formula method and dimensional analysis method. Nurse Educ Pract. 2010; 10(4): 233-7. doi: 10.1016/j.nepr.2009.11.011. PMID: 20018563.

5) Kouhestani HR, Baghcheghi N, Khosravi SH. Frequency, type and causes of medication errors in student nurses. Iran J Nurs. 2008; 21(53): 17-27.

6) Webster CS, Anderson DJ. A practical guide to the implementation of an effective incident reporting scheme to reduce medication error on the hospital ward. Int J Nurs Pract. 2002; 8(4): 176-83. doi: 10.1046/j.1440-172X.2002.00368.x.

7) Anderson DJ, Webster CS. A systems approach to the reduction of medication error on the hospital ward. J Adv Nurs. 2001; 35(1): 34-41. doi: 10.1046/j.1365-2648.2001.01820.x.

8) Nasiri $M$, Nasiri M, Adarvishi $S$, Hadigol $T$. The effectiveness of teaching anatomy by mobile phone compared with its teaching by lecture. J Med Educ Dev. 2014; 7(14): 94-103.

9) Namnabati M, Azar EF, Valizadeh S, Tazakori Z. Lecturing or Problem-based Learning: Comparing Effects of the Two Teaching Methods in Academic Achievement and Knowledge Retention in Pediatrics Course for Nursing Students. Iran J Med Educ. 2011; 10(4): 474-82. 
10) Khatooni M, Alimoradi Z, Samiei-Seiboni F, Shafiei Z, Atashi V. The impact of an educational software designed about fundamental of nursing skills on nursing students' learning of practical skills. J Clin Nurs Midwifery. 2014; 4(3): 9-16.

11) Moradi E, Mokhtari Nouri J, Ebadi A, Salari MM. Effectiveness of medical nuclear care nursing training on levels of learning by multimedia software. J Crit Care Nurs. 2010; 3(3): 0-0.

12) Hosseininasab D, Abdullahzadeh F, Feizullahzadeh H. The effect of computer assisted instruction and demonstration on learning vital signs measurement in nursing students. Iran J Med Educ. 2007; 7(1): 23-30.

13) Kaveevivitchai C, Chuengkriankrai B, Luecha Y, Thanooruk R, Panijpan B, Ruenwongsa P. Enhancing nursing students' skills in vital signs assessment by using multimedia computer-assisted learning with integrated content of anatomy and physiology. Nurse Educ Today. 2009; 29(1): 65-72. doi: 10.1016/j.nedt.2008.06.010. PMID: 18703258.

14) Feizalahzadeh H, Tafreshi MZ, Moghaddasi H, Farahani MA, Khosrovshahi HT, Zareh Z, et al. Development and Validation of a Theory-Based Multimedia Application for Educating Persian Patients on Hemodialysis. Comput Inform Nurs. 2014; 32(5): 242-7. doi: 10.1097/CIN.0000000000000052. PMID: 24642877.

15) Ebrahimpour F, Shahrokhi A, Ghodousi A. Patients' Safety and Nurses' Medication Administration Errors. IJFM. 2014; 20(1): 401-8.

16) Mansouri A, Ahmadvand A, Hadjibabaie M, Kargar M, Javadi M, Gholami K. Types and severity of medication errors in Iran; a review of the current literature. DARU Journal. 2013; 21(1): 1. doi: 10.1186/2008-2231-21-49.

17) Mirzaei M, Khatony A, Faramani RS, Sepahvand E. Prevalence, Types of Medication errors and Barriers to Reporting Errors by Nurses in an Educational Hospital in Kermanshah. Hayat. 2013; 19(3): 28-37.

18) Jukes L, Gilchrist M. Concerns about numeracy skills of nursing students. Nurse Educ Pract. 2006; 6(4): 192-8. doi: 10.1016/j.nepr.2005.12.002. PMID: 19040877.

19) Pauly-O'Neill S, Prion S. Using integrated simulation in a nursing program to improve medication administration skills in the pediatric population. Nurs Educ Perspect. 2013; 34(3): 148-53. doi: 10.5480/1536-5026-34.3.148.

20) Mansouri A, Ahmadvand A, Hadjibabaie M, Javadi M, Khoee SH, Dastan F, et al. A review of medication errors in iran: sources, underreporting reasons and preventive measures. Iran J Pharm Res. 2014; 13(1): 317. PMID: 24734052, PMCID: PMC3985240.

21) Ahmadieh M, Dehqanpoor M. The Effect of Using Group Work Skills in Mathematical Calculation of Medication Needed for Clinical Education in Nursing. Iran J Med Educ. 2005; 5(14).

22) Sung YH, Kwon IG, Ryu E. Blended learning on medication administration for new nurses: Integration of e-learning and face-to-face instruction in the classroom. Nurse Educ Today. 2008; 28(8): 943-52. doi: 10.1016/j.nedt.2008.05.007. PMID: 18599162.

23) Alsulami Z, Conroy S, Choonara I. Medication errors in the Middle East countries: a systematic review of the literature. Eur J Clin Pharmacol. 2013; 69(4): 995-1008. doi: 10.1007/s00228-012-1435-y. PMID: 23090705, PMCID: PMC3621991.

24) Armitage G, Knapman H. Adverse events in drug administration: a literature review. J Nurs Manag. 2003; 11(2): 130-40. doi: 10.1046/j.1365-2834.2003.00359.x.

25) Wolf Z, Hicks RW, Serembus J. Characteristics of medication errors made by students during the administration phase: a descriptive study. J Prof Nurs. 2006; 22(1): 39-51. doi: 10.1016/j.profnurs.2005.12.008.

26) Alinier G. Nursing students' and lecturers' perspectives of objective structured clinical examination incorporating simulation. Nurse Educ Today. 2003; 23(6): 419-26. doi: 10.1016/S0260-6917(03)00044-3.

27) Carpenter J. Interprofessional education for medical and nursing students: evaluation of a programme. Med Educ. 1995; 29(4): 265-72. doi: 10.1111/j.1365-2923.1995.tb02847.x.

28) McConville SA, Lane AM. Using on-line video clips to enhance self-efficacy toward dealing with difficult situations among nursing students. Nurse Educ Today. 2006; 26(3): 200-8. doi: 10.1016/j.nedt.2005.09.024.

29) Senn GJ. Comparison of face-to-face and hybrid delivery of a course that requires technology skills development. J Inf Technol Educ. 2008; 7(20): 267-84.

30) Ross JG. The effect of simulation training on baccalaureate nursing students' competency in performing intramuscular injection. Nurs Educ Perspect. 2015; 36(1): 48-9. doi: 10.5480/13-1075.1.

31) Lau K. Computer - based teaching module design: principles derived from learning theories. Med Educ. 2014; 48(3): 247-54. doi: 10.1111/medu.12357. 
32) Gladstone J. Drug administration errors: a study into the factors underlying the occurrence and reporting of drug errors in a district general hospital. J Adv Nurs. 1995; 22(4): 628-37. doi: 10.1046/j.13652648.1995.22040628.x.

33) Elliott M, Joyce J. Mapping drug calculation skills in an undergraduate nursing curriculum. Nurse Educ Pract. 2005; 5(4): 225-9. doi: 10.1016/j.nepr.2004.12.003. PMID: 19038203.

34) Gillham DM, Chu S. An analysis of student nurses' medication calculation errors. Contemp Nurse. 1995; 4(2): 61-4. doi: 10.5172/conu.4.2.61.

35) Nick Pima N, Gholamnejad H. Causes of Medication Errors by Nurses. J Sch Nurs Mid. 2009; 19(64):1 824.

36) Zahmatkeshan N, Bagherzadeh R, Mirzaee K. Analysis of the Types and Causes of Medication Errors by Nursing Staff at Selected Health Centers in Bushehr Province. Iranian South Medical journal. 2010; 13(3): 201-6.

37) Wright K. Barriers to accurate drug calculations. Nurs Stand. 2006; 20(28): 41-5. doi: 10.7748/ns2006.03.20.28.41.c4099.

38) Shams S, Khajehali N, Baghayee R. Comparing pharmacology knowledge and pharmaceutical calculations skill in Cardiac Care Unit (CCU) among nursing students of Oroumiyeh and Khouy. J Crit Care Nurs. 2013; 6(3): 181-8.

39) Haji Hosseini F, Sharifnia H, Nazari R, Rezai R, Saatsaz S. Basic Skills, Medications and Intravenous Therapy Nursing Students at the End of the Third Year. Orumieh Faculty of Nursing and Midwifery. 2012; 10(2): $0-0$.

40) Wright K. Can effective teaching and learning strategies help student nurses to retain drug calculation skills? Nurse Educ Today. 2008; 28(7): 856-64. doi: 10.1016/j.nedt.2008.01.002. PMID: 18304704.

41) Holland A, Smith F, McCrossan G, Adamson E, Watt S, Penny K. Online video in clinical skills education of oral medication administration for undergraduate student nurses: a mixed methods, prospective cohort study. Nurse Educ Today. 2013; 33(6): 663-70. doi: 10.1016/j.nedt.2012.01.006. PMID: 22341996.

42) Ma H, Bo W, Liu J, Jian D, Xie Y. Video feedback teaching method in teaching of abdominal physical examination. Frontier and Future Development of Information Technology in Medicine and Education: Springer. 2014; 2707-13. doi: 1007/978-94-007-7618-0-340.

43) Yoo MS, Son YJ, Kim YS, Park JH. Video-based self-assessment: Implementation and evaluation in an undergraduate nursing course. Nurse Educ Today. 2009; 29(6): 585-9. doi: 10.1016/j.nedt.2008.12.008. PMID: 19167789. 